FACULdADE DE CIÊNCIAS ECONÔ MICAS DA UFRGS

MACROECONOMIA DO BRASIL PÓS-1994 LUIZ CARLOS BRESSER-PEREIRA

DESENVOLVIMENTO ECONOMMICO, PREFERÊNCIA PELA LIQUIDEZ E ACESSO BANCÁRIO: UM ESTUDO DE CASO DAS MESORREGIÓES DE MINAS GERAIS

MARCO CROCCO, CLAUDIO BARRA DE CASTRO, ANDERSON CAVALCANTE E VANESSA DA COSTA VAL

FRIEDMAN E O MONETARISMO: A VELHA TEORIA QUANTITATIVA DA MOEDA E A MODERNA ESCOLA MONETARISTA

GENTIL CORAZZAE RODRIGO L. KREMER

BOLLHAS RACIONAIS, CICLO DE PREÇOS DE ATIVOS E RACIONALIDADE LIMITADA: UMA AVALIACAOO CRITICA DOS MODELOS NEOCLÁSSICOS DE BOLHAS ESPECULATIVAS JOSÉ LUIS OREIRO

VULNERABILITY INDICATORS OF THE TWIN CRISES: THE EAST ASIAN EPISODE

TITO BELCHIOR SILVA MOREIRA

IMPACTOS POTENCIAIS DA NEGOCIAÇÃO DA ALCA SOBRE OS INVESTIMENTOS EXTERNOS EM SERVIÇOS PROFISSIONAIS NO BRASIL

MICHEL ALEXANDRE, OTAVIANO CANUTO E GILBERTO TADEU LIMA

TEORIA MARXISTA DO VALOR: UMA INTRODUÇẢO ALFREDO SAAD FILHO

UM ESTUDO EMPIRICO DOS CICLOS POLITICO. ECONOOMICOS NO BRASIL

ATHOS PRATES DA SILVEIRA PREUSSLER E MARCELO SAVINO PORTUGAL

RELENDO CHANDLER, WILLIAMSON E NORTH PARA ENTENDER O PROCESSO DE FORMACĀO DAS ESTRADAS DE FERRO NO BRASIL

JEFFERSON ANDRONIO RAMUNDO STADUTO

WEIMAR FREIRE DA ROCHA IR. E CLAIITON ATAIDES DE FREITAS

MATRIZ DE INSUMO-PRODUTO PARA A ECONOMIA TURISTICA BRASILEIRA: CONSTRUCCÃO E ANÁLISE DAS RELAÇÓES INTERSETORIAIS

FRANCISCO CASIMIRO FILHO E JOAQUIM JOSÉ MARTINS GUILHOTO

SEÇĀO ESPECIAL: AVALIAÇŌES INICIAIS DA POLITTICA ECONÓMICA DO GOVERNO LULA

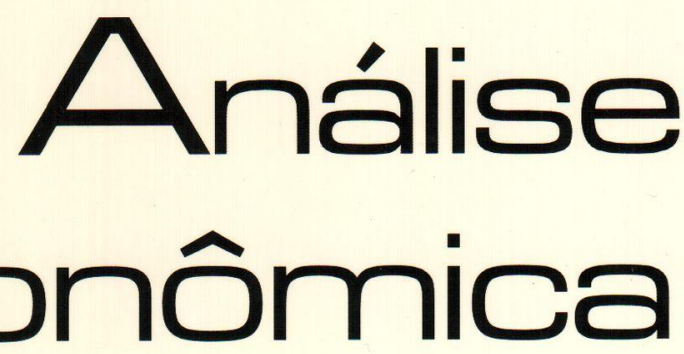


Universidade Federal do Rio Grande do Sul

Reitora: Profa. Wrana Maria Panizzi

Faculdade de Ciencias EConómicas

Diretora: Prof Pedro César Dutra Fonseca

Centro de Estudos e Pesquisas Economicas

Diretor: Prof. Gentil Corazza

Departamento de Ciéncias económicas

Chiefe: Prof. Ricardo Dathein

Curso de Pós. Graduação em Economia

Coordenador: Prof. Eduardo Pontual Ribeiro

Programa de Pós-Graduação em Desenvolvimento Rural

Coordenador: Prof. jalcione Almeida

CONSElHo EDITORIAL:

Carlos G. A. Mielitz Netto (UFRGS), Eduardo A. Maldonado Filho (UFRGS), Eduardo P. Ribeiro (UFRGS), Eleutério F. S. Prado (USP), Eugênio Lagemann (UFRGS), Fernando Cardim de Carvalho (UFRJ), Fernando Ferrari Filho (UFRGS), Fernando de Holanda Barbosa (FGV/RJ), Flávio Vasconcellos Comim (UFRGS), Gentil Corazza (UFRGS), Giácomo Balbinotto Netto (UFRGS), Gustavo Franco (PUC/RJ), Jan A. Kregel (UNCTAD), João Rogério Sanson (UFSC), Joaquim Pinto de Andrade (UnB), Jorge Paulo Araújo (UFRGS), Marcelo S. Portugal (UFRGS), Maria Alice Lahorgue (UFRGS), Paul Davidson (University of Tennessee), Paulo D. Waquil (UFRGS), Pedro C. D. Fonseca (UFRGS), Philip Arestis (Levy Economics Institut of Bard College), Roberto C. de Moraes (UFRGS), Ronald Otto Hillbrecht (UFRGS), Sabino da Silva Porto Jr. (UFRGS), Stefano Florissi (UFRGS) e Werner Baer (University of Illinois at UrbanaChampaign).

COMISSÃO EDITORIAL:

Eduardo Augusto Maldonado Filho, Fernando Ferrari Filho, Gentil Corazza, Marcelo Savino Portugal, Paulo Dabdab Waquil e Roberto Camps Moraes.

EDIroR: Prof. Fernando Ferrari Filho

Editor Adunnio: Prof. Gentil Corazza

SECRETÁrla: Clarissa Roncato Baldim

REVISÁO DE TEXTOS: Vanete Ricacheski

EDITORaÇão Eletrónica: Vanessa Hoffmann de Quadros

Fundador: Prof Antônio Carlos Santos Rosa

Os materiais publicados na revista Análise Econômica são da exclusiva responsabilidade dos autores. É permitida a reprodução total ou parcial dos trabalhos, desde que seja citada a fonte. Aceita-se permuta com revistas congêneres. Aceitam-se, também, livros para divulgação, elaboraçāo de resenhas e recensōes Toda correspondência, material para publicaçāo (vide normas na terceira capa), assinaturas e permutas devem ser dirigidos ao seguinte destinatário:

Análise Econômico

PROF FERNANDO FERRARI FILHO Revisła Análise Econômica - Av. João Pessoa, 52 CEP 90040-000 PORTO ALEGRE - RS, BRASL Telefones: (051) 316-3513 - Fax: (051) 316-3990 E-mail: rae@ufrgs.br

Ano 21, $n^{\circ} 39$, março, 2003 - Porto Alegre

Faculdade de Ciências Econômicas, UFRGS, 2003

Periodicidade semestral, março e setembro.

Tiragem: 500 exemplares

1. Teoria Econômica - Desenvolvimento Regional.

Economia Agrícola - Pesquisa Teórica e Aplicada -

Periódicos. I. Brasil

Faculdade de Ciências Econômicas,

Universidade Federal do Rio Grande do Sul 


\title{
O Que a Proposta de Autonomia para o BCB Esconde?*
}

\author{
João Sicsú **
}

\section{Introdução}

Esperança e Mudança: foram os sentimentos que elegeram Lula presidente em 2002. Contudo, já existe uma percepção generalizada nos meios mais bem-informados de que não houve qualquer mudança. Sendo assim, o governo Lula tem gastado grande parte de suas energias para explicar por que seguiu o caminho do continuísmo. Entretanto, alguns avaliam que as mudanças ainda estão por vir, outros já dizem claramente que este é o melhor caminho diante das circunstâncias.

Mas o continuísmo se deu exatamente pela área mais crucial de qualquer governo, a economia. As propostas e discursos do Presidente Lula, de seu Ministro da Fazenda, Antônio Pallocci, e do Presidente do Banco Central, Henrique Meireles, prometem mudar na direção oposta da onda de esperança que emergiu em 2002. Objetivam consolidar uma situação que em grande medida foi a responsável pela derrota eleitoral de Fernando Henrique Cardoso e de seu candidato no ano passado. Além de serem mudanças para consolidar o que foi repudiado pelos eleitores de Lula, não são graduais, lentas e nem cautelosas. São mudanças profundas e rápidas que vão impedir que reais mudanças venham a ocorrer. Uma das mudanças anunciadas, que o governo promete realizar em breve, será a formalização da autonomia operacional do Banco Central do Brasil (BCB) ${ }^{1}$.

\footnotetext{
- $\mathrm{O}$ autor agradece o apoio do CNPq.

" Professor-adjunto do Instituto de Economia da UFRJ.

${ }^{1}$ Em carta ao Fundo Monetário Internacional, datada de 28 de maio de 2003, o Ministro da Fazenda e o Presidente do Banco Central reafirmaram o compromisso de formalizar a autonomia do Banco Central do Brasil. Anunciaram ao Fundo "...a emenda constitucional que facilita a regulamentação do sistema financeiro do setor financeiro - um passo necessário à formalização da autonomia do Banco Central - foi aprovada." Esta carta está disponível no site www.fazeda.gov.br.
} 


\section{Autonomia versus independência}

Com autonomia operacional, o Banco Central terá liberdade para conduzir a política monetária, isto é, determinar a taxa de juros, com o objetivo de alcançar uma meta de inflação determinada seja pelo Ministério da Fazenda, seja pelo Conselho Monetário Nacional. O "bode" introduzido no debate é o termo independência que significaria que o Banco Central teria liberdade para determinar o seu objetivo (uma meta de inflação qualquer, por exemplo) e a política monetária. Neste último caso, um governo eleito com milhões de votos não teria nenhum poder sobre uma das mais importantes instituiçōes públicas, o Banco Central. Diferentemente, no caso da proposta de autonomia, diriam os defensores dessa idéia, o Banco Central estaria submetido ao objetivo determinado por aqueles que foram eleitos. Portanto, são contrários à independência, mas são ardorosos defensores da autonomia operacional.

Segundo Fischer (1995, p. 20), o modelo que vem sendo chamado de modelo de independência pode ser definido como um esquema em que o banco central teria independência de objetivos e instrumentos; e o modelo de autonomia como um esquema em que o banco central teria somente independência de instrumentos (ou independência operacional). No primeiro modelo, o banco central tem liberdade para definir a sua meta quantitativa de inflação e pode utilizar os instrumentos de política monetária com plena liberdade. É o caso do Banco Central dos Estados Unidos. No segundo modelo, o banco central pode livremente utilizar os instrumentos de política monetária visando alcançar um taxa de inflação preestabelecida. É o caso do Banco Central da Inglaterra. No primeiro caso, para se garantir que não haverá descontrole inflacionário, deve-se colocar na presidência do banco central um indivíduo que considere a estabilidade de preços como sendo o ativo mais valioso de um país portanto, um presidente bastante conservador.

Embora membros da equipe econômica do governo Lula, entre eles o presidente do Banco Central do Brasil, venham tentando levar vantagem no debate atual acerca do melhor formato institucional para o $\mathrm{BCB}$, introduzindo o "bode" da independência na discussão, em verdade, desejam um modelo híbrido que mistura características dos dois modelos apresentados. Desejam um banco central com um único objetivo quantitativo preestabelecido (mirando exclusivamente uma meta de inflação) e, ao mesmo tempo, um 
presidente bastante conservador para dirigir o Banco Central. $\mathrm{Na}$ prática, esse já é o caso do Brasil.

\section{O Objetivo do Banco Central}

Uma questão relevante a ser tratada é que, no bojo da discussão sobre a autonomia, se está definindo que o Banco Central terá um único objetivo: manter a inflação abaixo de um teto preestabelecido. Essa é a primeira e mais importante questão. Em verdade, autonomia para a tomada de decisão sobre questões que são essencialmente técnicas qualquer órgão público ou Ministério deve, em princípio, possuir. Há alguém que avalie que o Ministério da Saúde, ou o de Minas e Energia, deve tomar decisōes sob pressões políticas malignas? Mas há alguém propondo autonomia para os Ministérios? Ou para a Petrobrás? Não! Percebe-se, portanto, que a discussão verdadeira que está embutida na proposta de autonomia é sobre que papel deve desempenhar o Banco Central do Brasil. Qual deve ser o objetivo do Banco Central? Essa é a mais importante questão.

Efetivamente, não é o mais relevante, nesse debate, se os diretores e o Presidente do Banco Central devem ter mandatos fixos. Embora isto não seja tão relevante, é digno de destaque que dirigentes de um banco central não deveriam ganhar estabilidade no emprego por quatro anos ou mais, já que movimentam um dos preços mais importantes da economia, que é a taxa de juros - que afeta a vida de milhões indivíduos - portanto, os técnicos do BCB que controlam a taxa de juros devem ser substituídos a qualquer hora se estiverem conduzindo a política monetária de tal forma que contrarie os objetivos do governo. De forma análoga, se os diretores da Petrobrás ou do BNDES estão conduzindo de forma incorreta as políticas econômicas de suas instituiçōes, contrariando a orientação do governo, devem ser substituídos. Condutas técnicas incorretas ou incompetentes não podem ser protegidas por regras de estabilidade no emprego.

Voltemos ao ponto central. O mais relevante nesse debate, de fato, é a definição se o Banco Central deve buscar exclusivamente alcançar uma meta quantitativa de inflação ou se deve também tomar decisões balizadas pela necessidade de reduzir a taxa de desemprego. O que se pretende definir na proposta de autonomia é que as variaçôes da taxa de juros devem ser balizadas somente pelo 
objetivo de conter a inflação sem levar em conta qualquer outra variável real da economia. É preciso deixar claro que a taxa de juros, além de ser capaz de reduzir a inflação, também afeta a vida dos cidadãos em outros aspectos cruciais. Quando a taxa de juros sobe, pode reduzir as possibilidades de lucros empresariais e causar a demissão de muitos trabalhadores. Quando é reduzida, pode provocar o efeito contrário. Pode, então, melhorar a vida de muitos, abrindo-lhes a possibilidade de encontrar um posto de trabalho ou de realizar um bom negócio produtivo. Sendo assim, o Banco Central deve ter entre seus objetivos a busca do pleno emprego, a busca do crescimento econômico. O Banco Central dos Estados Unidos - o país mais bem-sucedido em termos de estabilidade macroeconômica na última década, isto é, cresceu com estabilidade preços - possui dois objetivos: controlar a inflação e buscar o pleno emprego.

\section{Controlando a Inflação com a Taxa de Juros}

Uma questão importante que também está escondida na proposta de autonomia é a afirmação de que a taxa de juros é o único e eficaz instrumento de combate a inflação. A experiência recente mostra que a taxa de juros deveria ser utilizada com muita cautela para conter a inflação. O resultado de uma elevação da taxa de juros é incerto sobre a manutenção da estabilidade dos preços. Se isto não fosse tão verdadeiro, deveríamos considerar a ex-diretoria do Banco Central, assim como a atual, como incompetentes, já que não conseguiram domar a inflação de acordo com as metas estabelecidas nos últimos dois anos, e possivelmente também agora em 2003, apesar de terem utilizado com total liberdade a taxa de juros para este fim. Ademais, a taxa de juros somente pode reduzir a inflação se for capaz de diminuir a demanda por investimento e consumo. É através da subtração do poder de gastar da sociedade que a elevação da taxa de juros inibe os empresários a reajustar seus preços - o mecanismo é simples: os empresários consideram que está difícil escoar a produção aos preços correntes, então, avaliam que seria muito mais dificil ainda realizá-la a preços reajustados.

Por outro lado, o resultado de variações positivas da taxa de juros sobre a vida de cada trabalhador ou empresário é quase certo. Foi este efeito, que pode ser nefasto, que em grande medida ajudou Lula a se eleger presidente durante a gestão de Armínio Fraga à frente do Banco Central. Nos últimos anos, as altas taxas de juros e as 
repetidas crises cambiais impediram a economia brasileira de crescer - gerando falências e demissões - e chamaram o voto para o candidato que poderia controlar a inflação sem custos sociais, gerando milhões de empregos. É lamentável, mas o Presidente Lula, manteve a mesma política que ajudou a derrotar seu adversário em $2002^{2}$.

Logo em janeiro de 2003, o Governo Lula corretamente considerou a inflação um grave problema a ser imediatamente atacado. A taxa de juros foi aumentada e é mantida em elevados patamares. Não se poderia duvidar que essa política antiinflacionária seria eficaz, ainda mais se aliada ao arrocho fiscal de geração de superávites primários superiores a 4,25\% do PIB (segundo dados oficiais, o superávit primário fiscal foi de $5,41 \%$ do PIB no primeiro semestre de 2003). Contudo, é amplamente reconhecido que essa tática antiinflacionária somente funcionou às custas de um desemprego que atingiu em junho, segundo dados do IBGE, a taxa record de $13 \%$. Portanto, a taxa de juros deve ser banida de uma arquitetura mais permanente de manutenção da estabilidade de preços. A inflação deve ser mantida sob controle através da utilização de diversos mecanismos como, por exemplo, a proibição de contratos de indexação de preços (inclusive de tarifas públicas, aluguéis ou salários), o uso de políticas de rendas de distribuição de ganhos de produtividade entre o capital e o trabalho, a implementação de políticas tarifárias capazes de absorver variaçōes não desejáveis do preço internacional do petróleo, o estabelecimento de negociações em câmaras setoriais, etc ${ }^{3}$.

\section{Governantes são irresponsáveis?}

Há ainda uma questão teórica fundamental que não tem sido explicitada pelos defensores da tese da autonomia do banco central. Há uma hipótese que está escondida do debate e que sustenta a proposta de autonomia do BCB. Esta hipótese é conhecida como hipótese do viés inflacionário (em inglês, é conhecida como inflationary bias) e tem o seguinte significado: deputados, senadores,

\footnotetext{
${ }^{2}$ Para uma discussão a respeito da opção de política econômica do Governo Lula, ver Sicsú (2003a).

${ }^{3}$ Para uma discussão detalhada sobre a utilização de instrumentos não monetários para o controle da inflação, ver Sicsú (2003b).
} 
ministros e o próprio presidente de um país são sempre irresponsáveis na condução da política monetária - mais precisamente, determinarão a taxa de juros de acordo com os seus interesses individuais mais mesquinhos, por exemplo, vão reduzir a taxa de juros em períodos pré-eleitorais para elevar o nível de emprego, ainda que isto cause inflação, para tentar colher frutos eleitorais. Acreditando no realismo desta hipótese, os defensores da tese da autonomia do banco central avaliam que seria melhor para uma economia que o governo e sua base de apoio parlamentar não tivessem a capacidade de influenciar a determinação da taxa de juros. Segundo os autonomistas, os parlamentares e dirigentes do governo somente teriam um objetivo: garantir a sua reeleição. Essa hipótese precisa ser debatida de forma mais detalhada.

Para que uma idéia seja debatida é preciso que saia dos porões, que venha para a luz do dia, que venha para a mesa de debates. Já que não é explicitada, pode-se especular por que tem sido omitida. Certamente, não será fácil convencer parlamentares e governantes de que são um tipo de ser cujo objetivo é meramente individual - e não social-coletivo. Ora, obviamente existem parlamentares e dirigentes de governo que são individualistas-eleitoreiros-populistas, mas considerá-los todos ou a parte influente como defensores apenas da renovação de seus mandatos está certamente longe da realidade. É fato, é história, que homens públicos com projetos coletivos têm sido o motor das grandes transformaçōes do capitalismo. Os grandes reformistas da nossa história são dirigentes com projetos essencialmente sociais-coletivos. Contudo, imaginemos que parlamentares e dirigentes do governo sejam convencidos de que realmente são seres eleitoreiros, então, uma pergunta emerge: qual o incentivo para um parlamentar individualista votar contra si mesmo, contra seus "ins. tintos", instituindo um banco central autônomo? Em outros termos: se um presidente de um país é um ser individualista-eleitoreiro e, portanto, se utiliza da taxa de juros como instrumento para se reeleger, por que abriria mão desse instrumento concedendo autonomia ao banco central? Esta é uma complicação teórica que a hipótese do viés inflacionário traz para os defensores da tese da autonomia do banco central.

Enfim, a autonomia do banco central é uma proposta como muitas outras (entre elas metas de superávites fiscais) para conter ímpetos dos políticos que são todos considerados individualistas, é uma barreira considerada eficaz, capaz de conter o viés inflacioná- 
rio. Os defensores da tese da autonomia consideram, portanto, que sempre haverá inflação em países que não possuem regras capazes de conter a natureza individualista daqueles que podem influenciar as decisões técnicas do banco central, transformado-as em decisões políticas com objetivos eleitoreiros ou populistas.

A hipótese do viés inflacionário é frágil. Primeiramente, sabemos que nem todos os políticos são irresponsáveis e estariam sempre dispostos a trocar a sua eleição (quase sempre incerta) pela instabilidade macroeconômica, gerando inflação. Segundo, e muito importante também, existem muitos países que não têm um banco central autônomo ou independente e possuem estabilidade de preços. Esse, por exemplo, era o caso do Japão e de muitos países europeus antes de aderirem à Comunidade. Além do mais, os anos dourados do capitalismo, 1950 e, especialmente, 1960, foram marcados por taxas elevadas de crescimento com estabilidade de preços e sem autonomia ou independência de banco central em grande parte dos países industrializados.

\section{Existe alternativa à proposta de autonomia do $B C B$ ?}

Sim. Seria um BCB que agiria de forma totalmente coordenada com o governo central e que teria o objetivo de auxiliar o Executivo a manter a estabilidade monetária e a buscar o pleno emprego. Um BCB de ação coordenada não poderia emitir moeda que causasse elevação dos preços e teria que controlar a taxa de juros levando em conta benefícios e custos sobre a inflação e o desemprego de acordo com critérios estabelecidos pelo governo. De forma mais precisa: quem tem que definir a taxa de juros no Brasil é o Ministro da Fazenda, que pode e deve ser auxiliado pela equipe econômica do governo, isto é, os membros que compōem os Ministérios do Planejamento e Fazenda e a diretoria do Banco Central. Diferentemente, um BC autônomo teria liberdade para tomar decisões que poderiam ser até contrárias aos interesses governamentais de mudança. Contudo, nenhuma política, e muito menos a política monetária, deveria ser desenhada de forma isolada (autônoma !!!), todas devem fazer parte de um plano global para atingir os objetivos do governo federal. 


\section{7 À Guisa de Conclusão}

Caso a proposta de autonomia do $\mathrm{BC}$ conquiste a bancada parlamentar do PT e de seus aliados e, por conseguinte, seja aprovada no Congresso Nacional, o Banco Central do Brasil terá total liberdade para determinar a política monetária, ainda que esta seja contrária aos objetivos do governo. Interessante é que o Presidente Lula tem reclamado, com razão, do excesso de autonomia das agências reguladoras dos serviços públicos que podem autorizar reajustes de tarifas. O Presidente, recentemente, reclamou que somente sabia dos aumentos das tarifas pela televisão, pelos jornais, e que o governo não pode interferir ou sequer influenciar a decisão de reajustes de preços tão importantes, tais como energia elétrica, telefonia e outros. O governo quer retirar a autonomia dessas agências, já que existe um desequilibrio: não pode interferir sobre os preços das tarifas, mas é cobrado e considerado culpado pela inflação corrente e pela queda do poder de compra dos salários. Dessa forma, o governo não tem o bônus de decidir, mas carrega o ônus do efeito da decisão.

A concepção que concedeu autonomia a essas agências reguladoras durante o governo de Fernando Henrique Cardoso é a mesma que está por trás da proposta de autonomia do BCB. Os autonomistas consideram que o governo faria mau uso se pudesse determinar os preços das tarifas públicas, o "instinto" eleitoreiropopulista predominaria novamente. Os autonomistas são, portanto, coerentes, e é bom que o governo Lula resolva suas incoerências. Se reclama da falta de autonomia para determinar o preço da telefonia por que abriria mão de determinar um preço muito mais relevante para toda a economia, a taxa de juros, com a formalização da autonomia do $\mathrm{BCB}$ ? Tomara que o Governo resolva suas incoerências assumindo a responsabilidade de decidir os rumos das políticas de juros e de preços das tarifas. Esta é a responsabilidade que o Presidente Lula recebeu quando obteve milhões de votos em 2002.

\section{Referências Bibliográficas}

Fischer, S. (1995). Central-bank independence revisited. American Economic Review, 85(2).

Sicsú, J. (2003a). Rumos e Definições da Política Econômica Brasileira: do plano A de FHC para o plano At de Lula. IN: de Paula, João Antonio, Economia Política da Mudança. Belo Horizonte: Editora Autêntica.

Sicsú, J. (2003b). Políticas não-monetárias de controle da inflação: uma proposta pós-keynesiana. Análise Econômica, 21(1), março. 